Revista Educação e Políticas em Debate - v. 7, n. 2, p. 289 -312, mai./ago. 2018 - ISSN 2238-8346

\title{
A Constituição Federal de 1988: os caminhos das políticas de democratização do acesso e permanência na educação superior como direito fundamental
}

\author{
The Federal Constitution of 1988: the access and permanence in the undergraduate studies \\ democratization policies ways as a fundamental right.
}

\section{La Constitution Fédéral 1988: les chemins des politiques de démocratisation d'accès et permanence dans l'éducation supérieur comme droit fondamentaal}

\author{
Daniela de Melo Crosara ${ }^{1}$ \\ Universidade Federal de Uberlândia \\ Leonardo Barbosa e Silva ${ }^{2}$ \\ Universidade Federal de Uberlândia
}

Resumo: O presente artigo tem por escopo analisar as principais políticas criadas para ampliar o acesso e a permanência no âmbito da educação superior a partir da promulgação da Constituição Federal de 1988, em especial a Lei $\mathrm{n}^{\circ}$ 12.711/2012, bem como o Programa Nacional de Assistência Estudantil. Especificamente, pretende identificar como o texto constitucional vigente contribui para que tais medidas possam ser elaboradas e instituídas, assim como analisar os avanços e desafios existentes para tais políticas, que visam materializar o direito fundamental à educação, previsto como direito social na Carta Constitucional, sob a perspectiva da equidade ou igualdade material.

Palavras-chave: Constituição de 1988. Educação Superior. Acesso. Permanência. Direito fundamental

\begin{abstract}
This paper aims to analyse the most important policies developed to enlarge access and permanence in the undergraduate studies since the Federal Constitution of 1988 promulgation, specially, the Law $n^{\circ} 12.711 / 2012$, as well as the student assistance policies. In particular, this research intends to identify in which way the Constitution in force contributes to elaborate and make those measures effective and also to analyse those policies challenges and advances, with the aim of materializing the fundamental right to education, written as a social right in the Constitutional Letter, under the equality perspective.
\end{abstract}

Key words: Constitution of 1988. Undergraduate Studies. Access. Permanence. fundamental right.

Resumeé: Le présent article a par objectif analyser les principales politiques formées pour amplifier l'accès et la premanence dans le cadre de l'éducation supériur à partir de la promulgation de la Constitution Fédéral de 1988 em particulier la Loi n 12711/2012, ainsi que le Programme National d'Assitence Étudiants. Specifiquement a l'intention d'identifier comme le texte constitutionnel em viguer contribuer à que telles mesures puissent être

\footnotetext{
${ }^{1}$ Doutra em Educação pela Universidade Federal de Uberlândia (UFU). Professora da Faculdade de Direito da UFU.E-mail: danielamcrosara@hotmail.com

2 Doutor em Sociologia pela Universidade Estadual Paulista Júlio de Mesquita Filho (UNESP). Professor da Universidade Federal de Uberlândia (UFU).E-mail: barbosaesilva.leonardo@ufu.br
} 
e'laboreé et institueés, ainsi qu'analyser les progrès et de désfis existentes pour telles politiques, qui visent matérialiser le droit fondamental à éducation prévu comme droit social dans la charte constitutionnelle, sous la perspective de l'équité ou de l'égalité materielle.

Mot-clé:Constitution 1988. Éducation Supérieur. Accès. Pemanence. Droit fondamental

\section{Introdução}

As construções de perspectivas de formulação de políticas públicas vocacionadas para a consecução da justiça social e da democratização do acesso e permanência educacional passam, necessariamente, pela análise da Constituição Federal, uma vez que tal norma firma compromissos sociais importantes, que não se reduzem em meras expectativas, mas a impositivos normativos de concretização dirigidos ao Estado, além de se constituir em parâmetro de validade da atuação do estatal.

Nesse sentido, o presente artigo pretende articular os princípios e regras que compõem o quadro normativo constitucional da educação superior enquanto direito fundamental, revelando o potencial de tais dispositivos para impor a materialização desse direito da maneira mais ampla, ou seja, como mecanismo de superação das desigualdades sociais, propiciando a inclusão de segmentos socialmente excluídos da universidade pública, não apenas no que diz respeito ao acesso, mas também no tocante à permanência e a sua consequência, a conclusão com qualidade. Objetiva, também, problematizar os principais desafios que as políticas de acesso e permanência enfrentam no cenário atual.

Para isso, serão analisadas pela perspectiva constitucional as políticas afirmativas de ingresso instituídas pela Lei $\mathrm{n}^{\circ}$ 12.711/2012 e as políticas de permanência (Assistência Estudantil), instituída pelo Decreto $n^{\circ}$ 7.234/2010, como binômio indissociável da concreção do direito à educação. A indissociabilidade das duas políticas reside no fato de que ampliar o acesso às pessoas que historicamente se encontravam apartadas do ensino superior, como negros, indígenas e aqueles grupos pertencentes aos quintis mais baixos de renda, impõe a necessidade de se implementar medidas que garantam a essas categorias a sua permanência e conclusão com qualidade, uma vez que a verdadeira inclusão se opera desde o ingresso até a conclusão, buscando superar obstáculos existentes na educação superior, tais como os ligados à renda, transporte, moradia, saúde, entre tantos. 
Permitir a entrada desses grupos e não conceder condições de fruição da educação fornecida pela universidade em seu aspecto amplo significa instituir política pública vazia de conteúdo e, portanto, inefetiva em seus escopos, o que torna obrigatória a materialização conjugada das duas medidas.

Para realizar a análise pretendida, o artigo irá, em um primeiro momento, delinear como a Constituição Federal vigente constitui-se em importante marco normativo que impõe ao Estado não só a obrigação de fornecer a educação, enquanto política pública e, portanto, um serviço público, mas fazê-lo materializando os princípios constitucionais do Estado Democrático de Direito delineados no texto constitucional.

Em seguida, será analisada a educação como direito social fundamental e como tal, destinada a materializar a igualdade de oportunidades para todos. Disso decorre, que todas as políticas públicas criadas para ampliar o acesso ao ensino superior e garantir a permanência nele são válidas em relação ao texto constitucional, além de se constituírem em dever do Estado e não mera discricionariedade, como é o caso da Lei $n^{\circ} 12.711 / 2012$, que instituiu as cotas para ingresso nas universidades e institutos federais para egressos do ensino médio público, com recortes específicos para negros, indígenas, pessoas com deficiência e ainda, com renda familiar per capita igual ou inferior a 1,5 s.m. No mesmo diapasão, se coloca a política de assistência estudantil, pois seu objetivo fundamental é impedir que as inúmeras vulnerabilidades operem privando estudantes da fruição do direito à educação, seja impedindo o acesso às oportunidades acadêmicas necessárias para uma formação qualificada, seja promovendo a exclusão do sistema de ensino superior através da evasão.

\section{0 marco constitucional para o combate às desigualdades}

No ano de 2018, a promulgação da Constituição da República Federativa do Brasil de 1988 completa seus 30 anos vividos em meio a avanços e crises institucionais. O contexto de sua elaboração remete à transição entre uma ditadura militar, que durou 21 anos, e um projeto auspicioso, que visava inaugurar um Estado formulado com bases constitucionais que garantissem a consolidação, em alguma medida, de uma democracia social em solo pátrio.

O processo de elaboração do texto constitucional não foi de simples consenso, tanto que durou mais de 1 ano, já que a Constituinte Congressual foi instaurada em 01 de fevereiro de 1987 e a Constituição foi promulgada em 05 de outubro de 1988. Os embates entre os diversos grupos e segmentos sociais, bem como as concessões feitas para que o texto fosse 
finalmente aprovado, demonstram como as bases constitucionais da fundação do atual Estado Democrático surgiram e seguem se realizando em meio a tensões sociais de maneira ampla. A título de exemplo, uma das grandes vitórias dos movimentos sociais à época diz respeito a aprovação no Regimento Interno da Constituinte da possibilidade de apresentação de emendas populares ao projeto, desde que tivessem 30 mil assinaturas e o endosso de 3 entidades legalmente constituídas. Contudo, ainda que tivesse sido possível emendas populares ao projeto - e que foram muito importantes para o avanço de diversas causas sociais - o texto final da Constituição, promulgado e vigente, não permite a emenda constitucional de iniciativa popular para a sua alteração, o que é um contrassenso, uma vez que o poder constituinte pertence ao povo (BARROSO, 1999, p. 121-131).

Dito isso, é preciso ressaltar que a Constituição em vigor hoje no Brasil avançou muito no tocante aos direitos sociais e à sua interpretação, correlacionando-os com a concreção do princípio da igualdade e da dignidade da pessoa humana. A Constituição de 1988 possui um extenso rol de direitos sociais, elencando-os entre os direitos fundamentais, além de criar todo um setor para tratar de tais direitos, entre eles a educação e a seguridade social, no título da Constituição denominado "Da Ordem Social”.

Soma-se a este status de fundamentalidade atribuído aos direitos sociais, a previsão entre os princípios do Estado Democrático de Direito da dignidade da pessoa humana (artigo $1^{\circ}$, inciso III da CF/1988), além da disposição, entre os objetivos fundamentais da República Federativa do Brasil (artigo $3^{\circ}$ da $\mathrm{CF} / 1988$ ), de uma série de metas ligadas à concreção da igualdade substancial, tais como construir uma sociedade livre, justa e solidária; erradicar a pobreza e reduzir desigualdades, assim como promover o bem de todos sem qualquer tipo de discriminação.

A grande questão é entender que o texto constitucional, ao trazer tais previsões, criou uma rede de proteção normativa que permite e até mesmo, impõe, a implementação de políticas públicas voltadas para a promoção da justiça social e responsável pela concretização de direitos tão importantes para a transformação da sociedade brasileira, como a ampliação da educação, não apenas nos anos fundamentais, mas no acesso dos grupos mais vulneráveis à educação superior, o que tem potencial suficiente para promover uma mudança da face dos atores que têm participação política, econômica, laboral, entre outros.

A Constituição vigente possui um papel central em nossa ordem jurídica, uma vez que ela é o paradigma de validade (ou constitucionalidade) das normas infraconstitucionais. Para além dessa função, a Constituição direciona como o Estado brasileiro deve se constituir: traça 
como a estrutura do poder institucionalizado deve se organizar, fixa um rol de direitos inalienáveis, indisponíveis, imprescritíveis e universais e prevê programas de ações para o Estado, por meio dos direitos sociais, que ele deve concretizar.

Justamente por prever um rol de direitos sociais e uma série de metas a serem atingidas pelo Estado, que muitos constitucionalistas definem a Constituição vigente como de cunho social e dirigente (CANOTILHO, 2015, p. 23). Bonavides afirma que a Constituição de 1988 é essencialmente "uma Constituição do Estado social", de tal forma que "os problemas constitucionais referentes a relações de poderes e exercício de direitos subjetivos têm que ser examinados e resolvidos à luz dos conceitos derivados daquela modalidade de ordenamento”, ou seja, tendo em mente que se trata de uma carta constitucional de "valores refratários ao individualismo no Direito e ao absolutismo no Poder" (1998, p. 336). No caso da atual Constituição, ao prever planos que devem ser alcançados, como os previstos no artigo $3^{\circ}$ acima exemplificados, dirige a ação estatal, que deve ir além de simplesmente se abster da invasão arbitrária na esfera privada, típica de Constituições Liberais, possuindo o dever de construir um tipo específico de Estado, em que o Estado de Direito, a democracia e a solidariedade se associam de modo a criar uma "base jusfundamental incontornável, que começa nos direitos fundamentais da pessoa e acaba nos direitos sociais" (CANOTILHO, 2015, p. 19).

Esse dirigismo na conformação estatal voltada à concreção de uma sociedade pautada na solidariedade, no pluralismo, no respeito à diferença e na preocupação em superar obstáculos que geram a desigualdade é percebido nos primeiros artigos da Constituição e vai se aprofundando nos títulos seguintes.

Ao anunciar a dignidade da pessoa humana como princípio fundamental do Estado Democrático de Direito (art. $1^{\circ}$, III) determina que o ser humano é o fim da ação estatal e nunca seu meio, vedando a objetivação ou coisificação humana. Mas para além disso, todos os direitos fundamentais são atraídos para o núcleo da dignidade e muitos dela irradiam, em especial pelo fato de que viver com dignidade implica na fruição de uma série de direitos, tais como saúde, educação, habitação, não discriminação, participação paritária nos espaços de decisão, distribuição justa de bens e vantagens, tratamento equânime, entre outros.

Os direitos sociais, assim, surgem como um rol necessário para garantir não só a dignidade, mas também a concreção do princípio da igualdade material ou substancial. A igualdade originariamente, enquanto princípio informador dos textos constitucionais, possuía uma acepção formal, ou seja, todos seriam iguais perante a lei. Tal fórmula, porém, típica de Estados de concepção marcadamente liberais do final do século XVIII e início do século XIX, 
não era suficiente para garantir que situações de assimetria fossem tratadas por meio de medidas diferenciadas, no sentido de suplantar as desigualdades. Assim, a partir de uma concepção de Estado de cunho social (surgida no final do século XIX e início do século XX), os contornos do princípio constitucional da igualdade se alargam, compreendendo que a isonomia ou a verdadeira equidade somente se realizaria na medida em que se desse tratamento diferenciado para aqueles que não se encontravam na mesma situação de vantagem que os demais, sob pena de se aprofundar as desigualdades com um tratamento isonômico para pessoas que se encontram em posições diferentes.

Em outras palavras, como os bens, direitos e situações de vantagens não são distribuídos de forma equânime na sociedade, compreender que a igualdade se realiza apenas elaborando leis que não tratem com discriminação as pessoas e os vários segmentos sociais não é suficiente para concretizar de fato a igualdade enquanto valor e princípio informador do Estado. Se torna necessária a previsão de direitos e a materialização de políticas que permitam que aqueles que se encontram marginalizados e excluídos, tenham acesso em igual medida a uma série de bens e vantagens dos quais estão apartados. Para realizar tal fim, os direitos sociais desempenham um importante papel na promoção da concreção de uma igualdade material ou substancial, na medida que impõem ao Estado a promoção de uma série de direitos, de serviços públicos e de oportunidades, tais como saúde, educação, moradia, previdência, direitos trabalhistas, entre outros.

Os direitos fundamentais sociais previstos na Constituição de 1988, conceitualmente, são definidos como "prestações positivas estatais, enunciadas em normas constitucionais, que possibilitam melhores condições de vida dos mais fracos, direitos que tendem a realizar a igualização de situações sociais desiguais” (SILVA, 1994, p. 258).

A previsão de um rol de direitos sociais com caráter de fundamentalidade na Constituição de 1988 representa, portanto, um marco juspositivo de combate à desigualdade de maneira ampla e de inclusão, uma vez que o seu reconhecimento e garantia estruturam o próprio princípio democrático, de maneira tal que a democracia somente se concretizará quando todos tiverem a possibilidade de igual participação na vida política do Estado, ou seja, “a democracia só é um processo ou procedimento justo de participação política se existir uma justiça distributiva no plano dos bens sociais” (CANOTILHO, 2015, p. 19).

Esta inclusão social e combate à desigualdade revelados pelos direitos sociais impõe uma igualdade de acesso aos bens sociais, como a educação, a moradia, a saúde, entre outros, 
uma vez que o próprio conceito de cidadania se modifica a partir de um paradigma estatal de caráter social.

\begin{abstract}
Não se trata de tentativa de simplesmente atenuar a miséria ou os mais baixos estados de pobreza pela aplicação dos direitos sociais. A desigualdade permanece com o ingresso destes direitos no campo da cidadania, mas passa a existir em seus objetivos a diminuição de diferenças entre as classes. Os direitos sociais buscam o aprimoramento do padrão de vida civilizada, a restrição da insegurança, a aproximação das diversas situações sociais em que os indivíduos se acham. (VIEIRA, 2009, p. 192).
\end{abstract}

Inquestionavelmente a Constituição de 1988 configura-se como um marco para o combate às desigualdades, tanto que, conforme exemplifica Arretche (2015, p. 1-13), a partir dela formou-se uma rede protetiva social, ao tornar a saúde pública universal, assistindo mesmo aqueles que não possuíam carteira assinada e permitindo a aposentadoria do trabalhador informal, ao contrário do que se passava na vigência das Constituições anteriores, incluindo assim, em tal rede de proteção, 60\% dos trabalhadores que antes da entrada em vigor da Constituição de 1988 se encontravam apartados de tais direitos sociais.

Portanto, um modelo de Estado com acepção social legitima e valida a adoção de políticas públicas para o combate à desigualdade, como é o caso da nossa Constituição ao instituir um extenso rol de direitos sociais, uma vez que passa a ser escopo estatal a promoção da justiça social, da solidariedade e a concretização de uma efetiva igualdade, objetivos esses expressamente previstos no artigo $3^{\circ}$ de seu texto e, na mesma medida, desenvolvidos por meio da previsão dos direitos sociais como fundamentais, além de prever como diretriz da ordem econômica a justiça social (artigo 170) e como princípio reitor da referida ordem econômica a "redução das desigualdades regionais e sociais" (artigo 170, inciso, VII).

Seguindo essa ordem de ideias, a adoção de políticas públicas voltadas para a eliminação ou diminuição da exclusão, bem como da promoção de justiça social e igualdade de oportunidades, contribui para a concreção de metas ou objetivos impostos ao Estado previstos constitucionalmente, mormente no artigo $3^{\circ}$ do texto constitucional, já mencionado.

Portanto, o acesso e permanência na educação, em todos os níveis, são questões que se ligam intrinsecamente à promoção da igualdade, a uma, por ser a educação importante mecanismo de transformação social, a duas pelo fato de todos terem o mesmo de direito de se educar, direito este inerente à condição humana. 


\section{A Constituição Federal de 1988 e o direito fundamental à educação}

A educação mereceu tratamento singular pela Constituição Federal de 1988, uma vez que esta, de maneira inédita, a arrolou como um direito fundamental social, conforme se depreende do artigo $6^{\circ}$ de seu texto.

O direito à educação, portanto, ganha relevo na medida em que, ao ser compreendido como direito fundamental de natureza social, guarda em si todas as características inerentes a esses direitos. Ser um direito fundamental significa constituir-se em "situações jurídicas sem as quais a pessoa humana não se realiza, não convive e, às vezes, nem mesmo sobrevive” e, por isso mesmo, deve ser, além de formalmente previsto, realizado concretamente (SILVA, 1994, p. 164). Aliás, todos os direitos fundamentais apresentam como características serem universais, inalienáveis, imprescritíveis e indisponíveis, de modo tal que, além de se dirigirem a todos e todas, não perecem, não podendo ninguém onerosa ou gratuitamente dele se dispor.

Além disso, enquanto direito fundamental, o direito à educação tem aplicabilidade direta e imediata (artigo $5, \S 1^{\circ}$ da $\mathrm{CF} / 1988$ ), sendo considerado pela melhor doutrina como cláusula pétrea, ou seja, não pode sofrer emendas que tendam a aboli-lo (artigo $60, \S 4^{\circ}$ da CF/1988) (BONAVIDES, 1998, p. 594).

O direito à educação conceitua-se como direito de instruir-se, de buscar o conhecimento necessário para a autodeterminação da pessoa humana. Além de ser um direito em si mesmo, e como tal deve ser oferecido e realizado de maneira igual entre os seres humanos, a educação é instrumental para o exercício de outros direitos, tais como a mobilidade social, o pleno emprego, sendo, ainda, indissociável da cidadania. Nos dizeres de Cury (2002)

Assim, seja por razões políticas, seja por razões ligadas ao indivíduo, a educação era vista como um canal de acesso aos bens sociais e à luta política e, como tal, um caminho também de emancipação do indivíduo diante da ignorância. Dado este leque de campos atingidos pela educação, ela foi considerada, segundo o ponto de vista dos diferentes grupos sociais - ora como síntese dos três direitos assinalados - os civis, os políticos e os sociais ora como fazendo parte de cada qual dos três. A magnitude da educação é assim reconhecida por envolver todas as dimensões do ser humano: o singulus, o civis, e o socius. O singulus, por pertencer ao indivíduo como tal, o civis, por envolver a participação nos destinos de sua comunidade, e o socius, por significar a igualdade básica entre todos os homens. Essa conjunção dos três direitos na educação escolar será uma das características do século XX. (CURY, 2002, p. 245) 
Via de consequência, a educação, ao restar prevista como um direito fundamental de caráter social, impõe ao Estado o dever de prestá-la de maneira isonômica a todos, uma vez que todos os direitos fundamentais são universais e que todos os direitos sociais existem para superar desigualdades, bem como surge o dever estatal de implementar políticas públicas para garantir o acesso à educação, que se garante por uma oferta ampla e inclusiva, e de sua fruição, garantida por políticas de permanência e conclusão.

Segundo Höfling (2001) a educação, em si mesma considerada, é uma política social, ou seja, uma "política pública de corte social, de responsabilidade do Estado -mas não pensada somente por seus organismos”, de tal forma que as políticas sociais, incluído as educacionais, "se situam em um tipo particular de Estado", permitindo a interferência estatal, "visando a manutenção das relações sociais de determinada formação social”, variando sua feição conforme se diferenciam as sociedades e as concepções de Estado (HÖFLING, 2001, p. 31-32).

Em suma, a legitimação da formulação de políticas públicas de acesso e permanência à educação deriva não apenas do caráter de política social da educação, mas igualmente do tratamento dado a ela enquanto direito social fundamental pelo texto constitucional. Assim, todas as políticas visando garantir a concreção da educação guardam essa natureza jurídica.

Vale ressaltar que o conceito de política pública não é uníssono no seio da Policy Sciences, "termo que designa o estudo das políticas públicas como ciência aplicada” (ANDREWS, 2005, p. 13). Apesar da diversidade de apresentações, parece adequado pensá-las como

ações intencionais de governos que contêm tanto algum ou alguns objetivos articulados, por mais que esses objetivos tenham sido precariamente identificados, justificados e formulados, quanto alguns meios para alcançalos, de novo, independentemente de quão bem ou mal interligados estejam esses meios ao (s) objetivo (s) (HOWLETT et ali, 2013, p. 6).

Políticas públicas contêm programas e estes contêm ações. Nesse sentido, seriam políticas públicas educacionais as políticas estatais que atuam no sentido de dar concreção aos dispositivos constitucionais que tratam do direito à educação.

A previsão do direito à educação no texto constitucional vem especificado nos artigos 205 e seguintes. Inicialmente, do artigo 205 se depreende que: a oferta da educação é dever do Estado (e da família); a finalidade da educação é a de garantir o pleno desenvolvimento da pessoa, o preparo para a cidadania e a qualificação para o trabalho.

A primeira consequência que se extrai de tal previsão é a de que, como o Estado tem o dever de prover a educação enquanto direito, ele deve fazê-lo de maneira que todos possam ter 
acesso e permanência no ensino, uma vez que a ação estatal deve ser pautada por uma atuação equânime, sem seletividade desarrazoada.

Dito isso, o Estado tem, assim, o dever, e não a discricionariedade, de implantar políticas públicas que garantam a ampliação do acesso ao ensino, em todos os seus níveis, bem como que garantam a permanência e a conclusão da educação, uma vez que decorre logicamente do direito de estar na escola, o direito de completar adequadamente todas as etapas educacionais. Essas assertivas são reforçadas pelas finalidades trazidas no próprio artigo 205 para a educação, quais sejam, a garantia do desenvolvimento pessoal, pleno exercício da cidadania e do trabalho. Ora, a cidadania e o trabalho são igualmente direitos fundamentais previstos na Constituição Federal, e se o seu gozo é impactado pela educação, como está insculpido no tex to do artigo 205, a oferta do ensino deve se dar da maneira mais ampla possível, assim como a garantia de sua conclusão, sob pena dos direitos à cidadania e ao trabalho serem cerceados. O mesmo se diz do desenvolvimento pessoal, que é decorrência direta do princípio da dignidade da pessoa humana, por sua vez, fundamento do Estado Democrático de Direito constituído pela Constituição de 1988 (artigo $1^{\circ}$, III da CF/1988).

Corroborando com tais exegeses, o artigo 206 da Constituição vigente traça os princípios reitores do ensino, entre eles, a igualdade de acesso e permanência na escola (artigo 206, I da CF/1988); a gratuidade do ensino público (artigo 206, IV da CF/1988) e a garantia do padrão de qualidade (artigo 206, VII da CF/1988).

Além disso, o artigo 208, $\$ 1^{\circ}$ da CF/ 1988 dispõe ser direito público subjetivo o acesso ao ensino obrigatório e gratuito. Ao afirmar se tratar de um direito público subjetivo, a Constituição garante a todas as pessoas a possibilidade de exigir do Estado a prestação do serviço público educacional em nível fundamental, o que denota a grande relevância dada pela Constituição ao ensino de forma geral e o grau de obrigação do Estado no provimento de tal direito.

No tocante ao ensino superior, a previsão constitucional leva a crer que esse deve ser oferecido segundo a capacidade de cada um (artigo 208, V da CF/1988), do que decorre que o Estado não tem o dever de oferecê-lo de forma universal, podendo selecionar os seus beneficiários pela capacidade, ou seja, por formas de seleção meritocráticas. Contudo, tais mecanismos de seleção não podem acirrar as desigualdades, uma vez que o direito à educação deve ser provido a todos pelo Estado e que a educação é, por força constitucional, importante mecanismo de combate às desigualdades sociais, já que é qualificada como um direito social. 
Sendo assim, ainda que se selecione os beneficiários do ensino superior público, o Estado deve implementar medidas que garantam o acesso da forma mais ampla (quantitativamente) e garantindo a participação dos grupos mais vulneráveis e sistematicamente excluídos da educação superior ( qualitativamente), sob pena de não realizar todos os compromissos impostos ao Estado no artigo $3^{\circ}$ da Constituição Federal e inerentes ao caráter social do direito à educação.

O perfil delineado pela Constituição ao direito à educação tem particularidades que devem restar inequívocas: a educação, para além de um direito exercido pelo indivíduo, contribui para a formação do tipo de sociedade que se elegeu ao se promulgar a nova Constituição, uma vez que a qualidade da educação enquanto direito social imprime nela a necessária direção ao combate às desigualdades; além disso, ao se vincular o direito à educação à materialização da cidadania e do trabalho, como o faz o artigo 205 da CF/1988, tem-se comprovado o seu importante papel como via de acesso à participação paritária na vida política e econômica do Estado.

A paridade de participação, por sua vez, é mecanismo imprescindível para a superação de assimetrias e, via de consequência, de concreção da igualdade material ou substancial, o que, por sua vez, está intrinsicamente ligada aos contornos sociais dados ao Estado brasileiro pela Constituição de 1988.

Segundo o conceito de justiça de Fraser (2007, p. 107-109) é preciso desfazer os arranjos institucionais que propiciem os tratamentos assimétricos ou de subordinação que levam várias categorias a serem excluídas de uma participação paritária na vida social, sendo o direito social fundamental à educação mecanismo para construir esta paridade, conforme restou consignado acima, por propiciar situações de vantagens significativas quando se trata de compreender todas as pessoas como detentoras do direito de serem parceiros integrais nas relações sociais e políticas, como coloca Fraser (2007, p, 109). Nesse sentido,

(...) ter negada a condição de parceiro integral na interação social e ser impedido de participar como um par na vida social, como consequência de padrões institucionalizados de valoração cultural que estabelecem alguém como desmerecedor de respeito e estima. Quando tais padrões de desrespeito e desestima são institucionalizados, eles impedem a paridade de participação, assim como certamente também o fazem as desigualdades distributivas (FRASER, 2007, p. 113).

Portanto, as políticas públicas que criam acesso e permanência na educação, em especial aos grupos vulneráveis e excluídos dos bens e vantagens sociais, implementam os objetivos traçados para o Estado no artigo $3^{\circ}$ da $\mathrm{CF} / 1988$, bem como são medidas inerentes à própria 
previsão da educação como direito fundamental social. Tais políticas, além de serem válidas constitucionalmente, são de promoção obrigatória do Estado, e não uma faculdade, como se depreende do artigo 206, I da CF/1988, que prevê a igualdade de acesso e permanência na escola. Ainda que muito se discuta no âmbito do direito constitucional sobre a eficácia dos direitos sociais, em especial como direitos subjetivos, é inequívoco, pela interpretação sistemática de todo o tex to constitucional, que se conferiu ao Estado um papel preponderante na superação das desigualdades, papel esse indeclinável, surgindo daí a obrigatoriedade de tal ente agir, sempre, na direção da promoção da igualdade.

Disso denota que não é possível retrocessos sociais em termos constitucionais, quando se trata das ações do Estado. Os seus paradigmas constitucionais de ação estão bem delineados e todos indicam seu compromisso obrigatório com a promoção do bem de todos sem qualquer tipo de discriminação, devendo superar as desigualdades (artigo $3^{\circ}$ da CF/1988).

A vedação de retrocessos sociais significa, em apertadas linhas, uma vez que sua análise não é o escopo do presente artigo, a proibição de que medidas estatais possam gerar a diminuição ou a supressão de direitos, em especial os sociais, não se tratando simplesmente de uma regressão, ou seja, “um simples voltar atrás”, de modo que, "nem todo ajuste, ainda que resulte em eventual restrição de direito fundamental, configura uma violação de direito, mesmo no campo da reversão (ainda mais quando parcial) de políticas públicas” (SARLET, 2015, p. 74). Seria considerado retrocesso social para SARLET (2015), no tocante aos direitos sociais, toda que qualquer medida que “implique em supressão ou restrição ilegítima dos níveis vigentes de proteção social” (SARLET, 2015, p. 74-75) .

A análise de tal proibição e seus alcances é de extrema importância no momento atual e, em especial, quando se faz um balanço dos avanços promovidos pelo tex to constitucional na promoção da igualdade e de direitos como a educação, já que o desmonte do Estado Social de Direito e dos direitos sociais que lhe são inerentes estão em progresso e ganham proporções mundiais, incluindo o Brasil (SARLET, 2015, p. 75). Nesse sentido, impõe-se colocar em foco, além da obrigação do Estado em promover estes direitos sociais, a vedação de que ele faça um giro de 180 graus em sua atuação, migrando de promotor para supressor de tais direitos, sob pena de, em se

admitindo uma ausência de vinculação mínima do legislador (assim como dos órgãos estatais em geral) ao núcleo essencial já concretizado na esfera dos direitos sociais e das imposições constitucionais em matéria de justiça social, estar-se-ia chancelando uma fraude à Constituição" (SARLET, 2015, p. 84). 
Do exposto é possível dizer que o financiamento de políticas sociais não pode sofrer revezes de modo a reduzir drasticamente a materialização dos direitos sociais e até mesmo suprimi-los. O argumento de escassez de recursos financeiros para a promoção de direitos sociais, tais como a educação, implicando em cortes significativos, significa uma afronta à proibição de retrocessos, princípio implícito do texto constitucional e derivado do Estado Democrático de Direito e da dignidade da pessoa humana (SARTLET, 2015, p. 85-90), sendo, portanto, medida inconstitucional. A isso, soma-se a já mencionada condição de cláusula pétrea dos direitos sociais, que impede modificações no próprio texto que possam reduzir direitos sociais, de forma que

De outra parte, invocada a ausência de recursos insuficientes para a manutenção de determinados direitos sociais ou políticas públicas, tal situação (da disponibilidade de recursos) não poderá ser imputável ao Poder Público, ainda mais quando existirem alternativas à disposição para evitar a supressão ou a diminuição de prestações sociais essenciais. (SARLET, 2015, p. 105)

De todo o exposto, é possível deduzir que a política afirmativa, como a prevista na Lei $\mathrm{n}^{\circ} 12.711 / 2012$, é política pública de Estado, uma vez que não se limita a traduzir um plano de governo (SECCHI, 2014, p.5), mas a materializar princípios constitucionais, como o direito fundamental à educação, a igualdade substancial, a dignidade da pessoa humana e a justiça social. Como tal, sua aplicação deve se dar de forma ampla, não permitindo interpretações que limitem o seu alcance. Por outro lado, impõem medidas concretizadoras que permitam que as pessoas ingressantes pelas cotas possam permanecer na universidade, uma vez que a ampliação do acesso não é suficiente para garantir a inclusão pretendida pela referida lei, sendo imperiosa a atuação coordenada de outras políticas que com ela dialoguem no sentido de permitir a consecução do direito à educação superior para aqueles que se vêm apartados sistematicamente desse nível de ensino.

Nessa linha de raciocínio, as políticas de assistência estudantil, assim como a política afirmativa para ingresso, constituem-se em importantes mecanismos de concreção do direito à educação, uma vez que os obstáculos materiais não podem constituir em óbice para a conclusão do ensino superior, sob pena de se relegar apenas às elites econômicas o direito de cursar a universidade pública, em inversão inequívoca de todo o caráter social construído acima para o direito à educação. 
Logo, o Programa Nacional de Assistência Estudantil, previsto no Decreto $\mathrm{n}^{\circ}$ 7.234/2010, ${ }^{3}$ constitui-se em política pública de materialização do direito à educação, compondo um importante arcabouço normativo de proteção social e que, como tal, está acobertado pela proibição do retrocesso, não podendo ser dilacerado sob o argumento da contenção de gastos, conforme de denota da citação acima de Sarlet (2015). Como ato normativo primário e autônomo, o decreto presidencial que prevê o programa, coloca como sendo seus objetivos:

Art. 2 ㅇ São objetivos do PNAES:

I - democratizar as condições de permanência dos jovens na educação superior pública federal;

II - minimizar os efeitos das desigualdades sociais e regionais na permanência e conclusão da educação superior;

III - reduzir as taxas de retenção e evasão; e

IV - contribuir para a promoção da inclusão social pela educação.

Percebe-se do artigo acima que se trata de política pública social contando com a imperatividade normativa que cria obrigações para a Administração Pública Federal, que se vê impelida a realizar os fins ali propostos. A fragilidade da veiculação da assistência estudantil por meio de em um decreto presidencial reside no fato de que a edição, modificação e revogação de tal política pode ficar dentro de âmbito de atuação do Presidente da República, o que enfraquece o debate democrático e representativo da matéria, como ocorre com as leis editadas pelo Poder Legislativo. No entanto, tratando-se de política pública de materialização do direito à educação e de promoção da inclusão social e combate às desigualdades, como dispõe o próprio artigo $2^{\circ}$ acima, a sua alteração e execução deve pautar-se pela observância da proibição do retrocesso.

Sendo assim, a seguir serão analisadas a Lei ${ }^{\circ}$ 12.711/2012, bem como a política de assistência estudantil, no sentido de demonstrar como tais ações têm o potencial de promover o acesso e permanência no ensino superior, concretizando os ditames constitucionais da

\footnotetext{
${ }^{3} \mathrm{O}$ decreto presidencial, como o é o Decreto $\mathrm{n}^{\circ} 7.234 / 2010$, é espécie normativa de competência do Presidente da República e só pode ser editado nas hipóteses previstas no artigo 84, VI da Constituição Federal. Enquanto ato normativo, não apresenta subordinação hierárquica em relação à legislação ordinária infraconstitucional, podendo ser considerado ato normativo de caráter primário, ou seja, não se presta apenas para regulamentar leis em sentido estrito, como ocorrem com os decretos regulamentares ( e que não podem ultrapassar os limites legais, nos termos do artigo 84, inciso IV), mas a tratar autonomamente das matérias expressamente previstas na Constituição, sem necessidade de ratificação do Congresso Nacional, uma vez que tais assuntos versam sobre atribuições inerentes à Administração Federal.
} 
igualdade material, dignidade da pessoa humana, direito à educação e os contornos sociais conferidos ao Estado Democrático de Direito pelo texto constitucional vigente.

\section{A Lei $n^{\circ}$ 12.711/2012: os avanços e desafios no acesso ao ensino superior}

Após 24 anos de vigência do texto constitucional, de décadas de luta do Movimento Negro Unificado, da adoção voluntária de várias universidades públicas e até mesmo de decisão paradigma do STF considerando válida a adoção de ações afirmativas para ingresso no ensino superior, tanto para negros e indígenas, quanto para as pessoas em situação de vulnerabilidade econômica (ADPF 186/DF)4, foi promulgada em 29 de agosto de 2012 a Lei $n^{\circ} 12.711$ que determinou a reserva de vagas para ingresso nas universidades públicas federais e institutos federais, nos seguintes termos:

Art. 1o As instituições federais de educação superior vinculadas ao Ministério da Educação reservarão, em cada concurso seletivo para ingresso nos cursos de graduação, por curso e turno, no mínimo 50\% (cinquenta por cento) de suas vagas para estudantes que tenham cursado integralmente o ensino médio em escolas públicas.

Parágrafo único. No preenchimento das vagas de que trata o caput deste artigo, $50 \%$ (cinquenta por cento) deverão ser reservados aos estudantes oriundos de famílias com renda igual ou inferior a 1,5 salário-mínimo (um salário-mínimo e meio) per capita.

Art. 3o Em cada instituição federal de ensino superior, as vagas de que trata o art. 1o desta Lei serão preenchidas, por curso e turno, por autodeclarados pretos, pardos e indígenas e por pessoas com deficiência, nos termos da legislação, em proporção ao total de vagas no mínimo igual à proporção respectiva de pretos, pardos, indígenas e pessoas com deficiência na população da unidade da Federação onde está instalada a instituição, segundo o último censo da Fundação Instituto Brasileiro de Geografia e Estatística IBGE. (BRASIL, 2012a).

Resumidamente, a lei das cotas determina que sejam reservadas $50 \%$ das vagas das universidades federais para os discentes oriundos da escola pública, onde tenham completado todo o ensino médio. Dentro desse grupo, $25 \%$ das vagas devem ser destinadas aos alunos que

\footnotetext{
4 A Arguição de Descumprimento de Preceito Fundamental é uma ação prevista no artigo $102, \S^{\circ}$ da Constituição Federal vigente e regulamentada pela Lei ${ }^{\circ} 9.882 / 1999$. Tal ação, que pode ser proposta apenas por alguns legitimados (como o Procurador Geral da República; Presidente da República; Partido Político com representação no Congresso Nacional, entre outros) é proposta diretamente no STF, visando declarar inconstitucional leis e atos do Poder Público, que serão considerados inconstitucionais, quando violem abstratamente preceitos fundamentais do texto constitucional, ou seja, os princípios e regras mais importantes previsto no corpo da Constituição.
} 
percebem até 1,5 salários mínimos como renda familiar per capita e $25 \%$ para alunos que percebem acima de 1,5 salários mínimos. Dentro de cada grupo de renda, deve-se reservar, por sua vez, vagas para pessoas negras, indígenas e com deficiência, em proporção ao de sua representatividade no ente da federação onde se encontra a universidade, conforme o último Censo do IBGE.

As ações afirmativas são medidas de cunho reparatório, focais e temporárias que têm por escopo a modificação do cenário de exclusão, removendo as barreias impeditivas de acesso de categorias excluídas de bens e vantagens socialmente relevantes, visando combater a desigualdade e, por consequência lógica, promover a igualdade substancial ou material. Segundo Gomes (2001):

[...] as ações afirmativas se definem como políticas públicas (e privadas) voltadas à concretização do princípio constitucional da igualdade material e à neutralização dos efeitos da discriminação racial, de gênero, de idade, de origem nacional e de compleição física (GOMES, 2001, p. 89).

São medidas de cunho reparatório por visarem recompor um quadro histórico de exclusão, em especial em relação os negros e indígenas, visando superar as situações de discriminação e desigualdade a que são submetidos tais grupos até os dias atuais. São medidas focais por não se dirigirem a todos indiscriminadamente, mas apenas aos grupos que se enquadrem na situação de exclusão descrita na lei.

Aqui vale destacar que o fato da Lei $n^{\circ} 12.711 / 2012$ reservar vagas para determinados grupos não se constitui em uma inconstitucionalidade por violação ao princípio da igualdade, ao contrário, o realiza em sua acepção material ou substancial, que é a exegese mais democrática do referido princípio, uma vez que autoriza o tratamento diferenciado para segmentos que estão em condições de desigualdade, e a diferença de tratamento seria para garantir a superação dessa desigualdade. Nesse sentido, entendeu o Supremo Tribunal Federal, na ADPF 186/DF, conforme se depreende do acórdão proferido quando da análise da referida ação:

Vê-se, pois, que a Constituição de 1988, ao mesmo tempo em que estabelece a igualdade de acesso, o pluralismo de ideias e a gestão democrática como princípios norteadores do ensino, também acolhe a meritocracia como parâmetro para a promoção aos seus níveis mais elevados. Tais dispositivos, bem interpretados, mostram que o constituinte buscou temperar o rigor da aferição do mérito dos candidatos que pretendem acesso à universidade com o princípio da igualdade material que permeia todo o Texto Magno. Afigurase evidente, de resto, que o mérito dos concorrentes que se encontram em situação de desvantagem com relação a outros, em virtude de suas condições 
sociais, não pode ser aferido segundo uma ótica puramente linear, tendo em conta a necessidade de observar-se o citado princípio (BRASIL, 2012b, p. 17. Acórdão).

As políticas focais, como as ações afirmativas, para estes casos, são preferidas em relação a políticas universais por serem capazes de atingir situações específicas que as políticas universais não são capazes de abarcar com o mesmo grau de profundidade. No caso da educação, políticas universais como a melhora da educação pública, por exemplo, não dão conta sozinhas da mudança no quadro geral de desigualdades, como estão submetidas as pessoas negras e indígenas, uma vez que sua exclusão se deve, em grande monta, em face de barreira invisíveis que não são superadas por políticas universais isoladamente (GUIMARÃES, 2009, p. 188-189).

Outra característica importante das ações afirmativas, e necessária para não recaírem em inconstitucionalidade, está em seu caráter temporário, vigendo enquanto persistirem as desigualdades, tanto que a Lei $n^{\circ} 12.711 / 2012$ prevê expressamente a sua revisão após 10 anos de sua vigência. Em não subsistindo mais as situações de desigualdade que fundamentaram a formulação da política afirmativa, deve-se cessar sua execução, sob pena de promover medidas diferenciadoras desarrazoadas e, portanto, inconstitucionais.

Ainda que em meio a muitas polêmicas e desconfianças, a implementação das cotas para ingresso nas universidades públicas já conseguiu, em pouco tempo de execução, uma modificação nos quadros de representatividade de negros e pessoas oriundas dos extratos sociais mais baixos economicamente, demonstrando o grande potencial inclusivo e de promotor de paridade representativa das cotas.

Após a vigência da Lei n ${ }^{\circ}$ 12.711/2012, os dados publicados por uma pesquisa realizada pelas ANDIFES - Associação Nacional dos Dirigentes das Instituições de Ensino Superior divulgada em 2016, revelam quantitativamente a mudança no perfil dos alunos das universidades federais. Segundo a pesquisa, diminuiu o percentual de alunos que se autodeclararam brancos nas universidades federais, passando para 45\% em 2014, sendo negros $47,57 \%$ dos alunos no referido ano, ressaltando que em 2010, segundo o IBGE, $75 \%$ dos universitários se autodeclaravam brancos (ANDIFES, 2016, p. 12-13). No tocante a renda, segundo a mesma pesquisa, tem-se que houve um aumento dos que compõem os quintis mais baixos de renda em relação a 2010 . Nesse ano, 8,33\% dos alunos tinham renda familiar bruta de até 1 salário-mínimo, 26,47\% tinham renda até 2 salários mínimos e 40,66\% com renda familiar bruta de até 3 salários mínimos. Em 2014, o número de participação dos três extratos 
aumentou para $13,21 \%$, para os alunos com renda familiar bruta de até 1 salário-mínimo; 36,65\% com até 2 salários mínimos e 51,43\% até 3 salários-mínimos (ANDIFES, 2016, p. 22).

Assim, pelos números acima ventilados, observa-se que a Lei $n^{\circ}$ 12.711/2012 vem cumprindo o papel de concretizar os princípios constitucionais que norteiam significativamente o Estado Social Democrático de Direito previsto na Constituição Federal de 1988, quais sejam, o da justiça social, combate às desigualdades e consequente promoção da igualdade material, direito à educação, dignidade da pessoa humana, entre outros.

Tais políticas, no entanto, somente encontraram espaço de materialização, apesar de serem pleiteadas historicamente pelos segmentos vulneráveis, sob o pálio da Constituição de 1988, que criou um ambiente normativo propicio para a promoção da igualdade.

Obviamente que a política afirmativa possui suas limitações, entre elas pode se destacar o fato de ser aplicada por meio de um processo seletivo que, pela sua própria natureza, ainda exclui em termos brutos uma quantidade significativa de pessoas que se enquadram no perfil dos cotistas, uma vez que a educação superior não é universal e a política afirmativa não soluciona o gargalo da conclusão do ensino médio que é um grande problema para o acesso ao ensino superior.

Nesse sentido é a conclusão do Estudo Técnico de $n^{0}$ 04/2014 da Secretaria de Avaliação e Gestão da Informação (SAGI), feito com base na Pesquisa Nacional por Amostragem de Domicílios (PNAD) dos anos 2001 a 2012, para o qual "parte da explicação do baixo acesso da população pobre aos anos mais avançados da escola básica pode se explicar pela evasão escolar que ocorre antes que esses jovens cheguem ao EM ou na transição do EF para o Médio" (BRASIL, 2014c, p. 20).

Mesmo assim, a representatividade proporcional intramuros contribui para a construção de uma universidade plural e democrática, abrindo espaço para a realização de uma cidadania mais completa.

\section{$4 \mathrm{O}$ decreto $n^{\circ}$ 7.234/2010: os avanços e desafios na permanência no ensino superior}

Aquilo que se convencionou chamar de política de permanência é, na verdade, a política de assistência estudantil. Todavia, antes de analisá-la, seria bom defini-la. Tomando por base o que sugere o Fórum Nacional de Pró-reitores de Assuntos Estudantis, pode-se compreender a política de assistência estudantil como sendo 
um conjunto de princípios e diretrizes que norteiam a implantação de ações para garantir o acesso, a permanência e a conclusão de cursos de graduação dos estudantes das IFES, na perspectiva da inclusão social, formação ampliada, produção do conhecimento, melhoria do desempenho acadêmico e da qualidade de vida (FONAPRACE/ANDIFES; PROEX/UFU, 2012, p. $63)$.

Deste modo, e antes de tudo, a política de assistência estudantil seria uma resposta ao reconhecimento de que a sociedade se encontra cindida e que tal cisão expõe pessoas a condição de marginalidade, de exclusão social e de vulnerabilidade.

A vulnerabilidade parece ser uma categoria adequada e cara ao campo científico e político do serviço social. A mesma categoria está presente no Programa Nacional de Assistência Social (PNAES) e contribui de forma definitiva na orientação das ações de promoção de igualdades nas IFES. Pode-se entendê-la como a perda ou fragilidade

de vínculos de afetividade, pertencimento e sociabilidade; ciclos de vida; identidades estigmatizadas em termos étnico, cultural e sexual; desvantagem pessoal resultante de deficiências; exclusão pela pobreza e, ou, no acesso às demais políticas públicas; uso de substâncias psicoativas; diferentes formas de violência advinda do núcleo familiar, grupos e indivíduos; inserção precária ou não inserção no mercado de trabalho formal e informal; estratégias e alternativas diferenciadas de sobrevivência que podem representar risco pessoal e social(BRASIL; CONSELHO NACIONAL DE ASSISTÊNCIA SOCIAL, 2004).

Pensada desta forma, se tomaria a vulnerabilidade como um marcador importante na definição do acesso às oportunidades acadêmicas, do rendimento acadêmico, das condições de evasão e retenção, nos desejos de mobilidade, na inserção em programas e projetos, na formação qualificada, entre outras. Sobre e contra esta vulnerabilidade agiria a política de assistência estudantil, com vistas a uma permanência qualificada.

No Brasil, nunca houve uma política nacional de assistência estudantil, somente programas, não obstante haja projetos de lei em tramitação para este fim. Desde as primeiras ações neste campo, no ano de 1928 (CARVALHO, 2013), até o presente, o único documento nacional que orienta as políticas de permanência é o Programa Nacional de Assistência Estudantil (PNAES).

O PNAES está disposto no Decreto n 7.234/2010 (BRASIL, 2010), anunciando dez áreas de atuação (moradia estudantil, alimentação, transporte, assistência à saúde, inclusão digital, cultura, esporte, creche e apoio pedagógico e acessibilidade) e o escopo do público atendido (estudantes de graduação de cursos presenciais prioritariamente, com origem em escola pública e renda per capta familiar mensal de até um salário mínimo e meio). O mesmo 
corte foi definido pela Lei Federal $\mathrm{n}^{\circ}$ 12.711/2012, quando define ao menos 50\% (cinquenta por cento) das vagas das IFES para estudantes que tenham cursado integralmente o ensino médio em escolas públicas. Do público contemplado neste percentil, “50\% (cinquenta por cento) deverão ser reservados aos estudantes oriundos de famílias com renda igual ou inferior a 1,5 salários-mínimos (um salário-mínimo e meio) per capita”. Note-se que a Lei de Cotas e o PNAES, atuando nas dimensões de acesso e permanência, alinham seus critérios para definição da população coberta.

Tal como formulado, o PNAES compreende que as ações de assistência estudantil devem ser implementadas "de forma articulada com as atividades de ensino, pesquisa e extensão, visando o atendimento de estudantes regularmente matriculados em cursos de graduação presencial das instituições federais de ensino superior” (art. $3^{\circ}$ ). Daqui se depreende que o programa não gera cobertura para discentes de pós-graduação, escolas técnicas federais ou vinculados aos programas de educação à distância.

Sobre os objetivos do programa, como já fora apontado anteriormente, destacam-se $\left(\operatorname{art.} 2^{\circ}\right)$ : I - democratizar as condições de permanência dos jovens na educação superior pública federal; II - minimizar os efeitos das desigualdades sociais e regionais na permanência e conclusão da educação superior; III - reduzir as taxas de retenção e evasão; e IV - contribuir para a promoção da inclusão social pela educação. Novamente, em consonância com a Constituição, vê-se aqui a percepção de que a educação é um direito em si e, a um só tempo, instrumental para outros. Não por outra razão, a assistência estudantil é tida como caminho para fruir o direito à educação e ter promovido a inclusão social.

Não obstante todos os avanços aqui representados, alguns apontamentos sobre os desafios são necessários para dar conta dos limites vividos e os passos a serem dados. Inicialmente, deve-se levar em consideração que os recursos orçamentários destinados ao programa se comportaram de forma ascendente até o ano de 2016, apresentando queda nos dois seguintes (COSTA \& BARBOSA e SILVA, 2018). Para os anos de 2018 a redução foi de $19 \%$, ameaçando os objetivos do programa.

Além disso, deve-se ressaltar que as ações em assistência estudantil orientadas pela definição de vulnerabilidade trazida neste trabalho estão num patamar de complexidade e alcance superiores ao que estabelece o PNAES. Enquanto o PNAES recorta a prioridade sobre população discente, elegendo oriundos de escolas públicas com renda de até 1,5 salários mínimos, ele deixa de lado várias outras formas de exclusão que isoladas ou somadas produzem redução no acesso ao direito à educação. 
Ainda sobre os desafios, não obstante se tenha clareza que a assistência estudantil seja capaz de ampliar possibilidade de se reduzir os indicadores de retenção e evasão, além de contribuir para uma formação com mais qualidade (COSTA \& BARBOSA e SILVA, 2018), a extensão de sua cobertura ainda não atinge o público alvo, nem mesmo aquele que é sua prioridade.

\section{Evolução do quantitativo de bolsistas e cotistas das IFES 2012-2016}

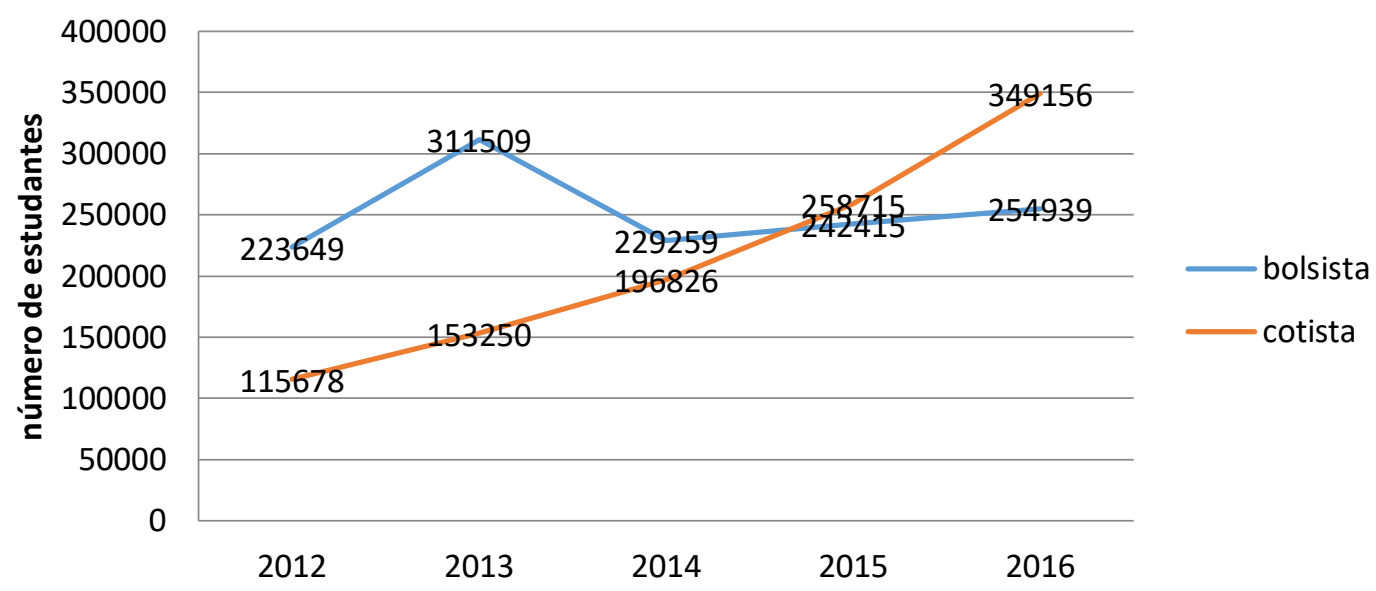

Fonte: (COSTA \& BARBOSA e SILVA, 2018)

Tal como informa o gráfico acima, desde 2015 o número de estudantes cotistas é superior ao número de estudantes cobertos pelas ações de assistência estudantil nas IFES. Isso significa que há um descompasso entre as políticas de acesso e as de permanência, exigindo reforço da segunda para que se tenha a garantia do direito. Ainda neste diapasão, deve-se salientar que é possível também realizar a mesma reflexão estratificando as modalidades de cotas, para buscar o entendimento sobre situações particulares. Para tanto se pode lançar mão do estudo realizado por Costa e Barbosa e Silva (2018), que se atesta que

Do exposto, percebe-se que a proteção da chamada "ação social", muito embora crescente, a) cobre menos quem não ingressou pelas cotas, b) dentre cotistas, cobre principalmente estudantes cuja vulnerabilidade determinante da reserva de vagas foi a renda, mas c) em todas as situações, o percentual de cobertura é muito baixo, oscilando entre aproximadamente um quarto e um terço do público demandante.

Por fim, cabe ressaltar que o PNAES, tal como se conhece, está regulamentado por um decreto presidencial, sem status de lei. Seus pés de barro são a prova de que a sua institucionalidade frágil fica à sorte dos governos, quando deveria ser política de Estado.

Assim, muito embora seja nítido o interesse em fazer do PNAES um programa capaz de responder adequadamente ao conteúdo da Carta Magna, alguns de seus desafios ainda 
operam no sentido de inibir o gozo do direito à educação, exigindo ampliação de sua eficácia e efetividade.

\section{Conclusões}

Desde a promulgação da Constituição Federal de 1988, o Brasil trilhou caminho significativo em vias de concretizar o direito à educação superior de maneira mais ampla.

Em que pese o fato de existir muito espaço ainda para medidas mais efetivas de tais direitos, ou seja, que incluam mais os extratos sociais vulneráveis, não se pode negar que os contornos constitucionais, ainda que em tese, permitem e legitimam ações no sentido de garantir a inclusão do maior número de pessoas na educação superior.

No caso específico da Lei n ${ }^{\circ}$ 12.711/2012 tem-se política pública de materialização dos objetivos do Estado Democrático de Direito, delineados no artigo $3^{\circ}$ do texto constitucional, pois permite o combate à pobreza, à diminuição de desigualdades e da discriminação, atuando de acordo com o artigo 206 da Constituição que prega entre os princípios reitores do direito à educação o acesso e a permanência em igualdade de condições.

Da mesma forma, o Decreto n ${ }^{\circ}$ 7.234/2010 institui o Programa Nacional de Assistência Estudantil para criar as condições de permanência para estudantes vulneráveis, sobretudo aqueles de origem no ensino público e com renda per capta de até 1,5 salários mínimos, agindo no sentido de impedir que as desigualdades sociais atuem bloqueando o acesso a um direito.

Entretanto, como se pode perceber, ainda há grandes desafios a serem enfrentados, sobretudo na capacidade de responder adequadamente à natureza e a grandeza do público vulnerável das IFES. Ainda assim, importa salientar que os avanços são significativos, não obstante insuficientes.

\section{Referências}

ANDREWS, Christina W. As policy scienes como "ciência": método e reificação, Perspectiva, São Paulo, v. 27, p. 13-35, 2005.

ARRETCHE, Marta. A metade cheia ou a metade vazia do copo? São Paulo, 2015a. Disponível em:https://www.oxfam.org.br/publicacoes/cada-vez-mais-desigual/a-metade-cheia-ou-ametade-vazia-do-copo. Acesso em: 18 jan. 2017.

ASSOCIAÇÃO NACIONAL DOS DIRIGENTES DAS INSTITUIÇÕES DE ENSINO SUPERIOR. Perfil socioeconômico e cultural dos estudantes de graduação das instituições federais de ensino superior brasileiras 2014. Uberlândia: Fonprace/Cepes-UFU, 2016. 
BARROSO, Pérsio. Constituinte e Constituição: participação popular e eficácia constitucional. Curitiba:Juruá, 1999.

BONAVIDES, Paulo. Curso de direito constitucional. 7. ed. São Paulo: Malheiros, 1998.

BRASIL. Constituição (1988). Constituição da República Federativa do Brasil de 1988. Brasília, DF: Senado Federal, 5 out. 1988. Disponível em: http://www.planalto.gov.br/ccivil_03/constituicao/constituicao.htm. Acesso em: 12 nov. 2016.

BRASIL. Lei $\mathrm{n}^{\circ} 12.711$, de 29 de agosto de 2012. Dispõe sobre o ingresso nas universidades federais e nas instituições federais de ensino técnico de nível médio e dá outras providências. Diário Oficial da União, Brasília, DF, 30 ago. 2012a. Disponível em: <http://www.planalto.gov.br/ccivil_03/_ato2011-2014/2012/lei/112711.htm>. Acesso em: 12 nov. 2016.

BRASIL. Ministério do Desenvolvimento Social e Combate à Fome. Secretaria de Avaliação e Gestão da Informação. Acesso e evasão na educação básica: as perspectivas da população de baixa renda no Brasil. Brasília, DF, 2014. (Estudo técnico, n. 04/2014).

BRASIL. Supremo Tribunal Federal. Arguição de Descumprimento de Preceito Fundamental $n^{\circ}$ 186-DF. Relator: Ministro Ricardo Lewandowski. Brasília, DF, 25 abr. 2012b. Disponível em: http://www.stf.jus.br/portal/processo/verProcessoAndamento.asp?

numero $=186 \&$ classe $=\mathrm{ADPF} \&$ origem $=\mathrm{AP} \&$ recurso $=0 \&$ tipoJulgamento $=\mathrm{M}>$. Acesso em: 25 abr. 2015.

BRASIL. Presidência da República. Decreto n 7.234/2010. Decreto nº 7234. . 29 jul. 2010.

CANOTILHO, J. J. Gomes. O direito constitucional como ciência e direção: o núcleo essencial de prestações sociais ou a localização incerta da sociabilidade, in CANOTILHO, J. J. Gomes; CORREIA, Marcus Orione Gonçalves; CORREIA, Érica Paula Barcha (org.). Direitos fundamentais sociais, São Paulo: Saraiva, 2 ed., 2015, p. 11-33.

CARValho, S. C. DA S. Avaliação da eficácia da Política Pública de Assistência Estudantil na Universidade Federal de Lavras. 2013.

COSTA, N. C. D.; BARBOSA E SILVA, L. Acesso e permanência em desproporção: as insuficiências do Programa Nacional de Assistência Estudantil. Comunicação em evento apresentado em III Encontro Nacional de Políticas Públicas. São Paulo, 2018.

CURY, Carlos Roberto Jamil. Direito à educação: direito à igualdade, direito à diferença. Cadernos de Pesquisa, n. 116, p. 245-262, jul. 2002. Disponível em: $<$ http://www.scielo.br/scielo.php?script=sci_arttext\&pid=So 100-15742002000200010 >. Acesso em: 22 nov. 2016.

FRASER, Nancy. Reconhecimento sem ética? Lua Nova, São Paulo, n. 70, p. 101-138, 2007.

GOMES, Joaquim Benedito Barbosa. Ação afirmativa e o princípio constitucional da igualdade. Rio de Janeiro: Renovar, 2001. 
GUIMARÃES, Antônio Sérgio Alfredo. Racismo e antirracismo no Brasil. 3. ed. São Paulo: Ed. 34, 2009.

HÖFLING, Eloisa de Mattos. Estado e políticas (públicas) sociais. Cadernos Cedes, Campinas, SP, ano 21 , n. 55 , p. 30-41, nov. 2001.

HOWLETT, M.; RAMESH, M.; PERL, A. Política pública: seus ciclos e subsistemas-uma abordagem integral. São Paulo: Campus, 2013.

IBGE. Censo Demográfico 2010. Rio de Janeiro, 2010. Disponível em: <http://censo2010.ibge.gov.br/resultados.html>. Acesso em: 22 set. 2015.

MELlo, Celso Antônio Bandeira de. O conteúdo jurídico do princípio da igualdade. 3. ed. São Paulo: Malheiros, 2014.

SARLET, Wolfgan Ingo. Dignidade (da pessoa) humana e direitos fundamentais na Constituição Federal de 1988. Porto Alegre: Livraria do Advogado, 10 ed., 2015.

SARLET, Wolfgan Ingo. Segurança social, dignidade da pessoa humana e proibição do retrocesso: revisitando o problema da proteção dos direitos sociais, in CANOTILHO, J. J. Gomes; CORREIA, Marcus Orione Gonçalves; CORREIA, Érica Paula Barcha (org.). Direitos fundamentais sociais, São Paulo: Saraiva, 2 ed., 2015, p. 69-109.

SECCHI, Leonardo. Políticas públicas: conceitos, esquemas de análise, casos práticos. 2. ed. São Paulo: Cengage Learning, 2014.

SILVA, José Afonso da. Curso de direito constitucional positivo. 9. ed. São Paulo: Malheiros, 1994.

VIEIRA, Evaldo. Os direitos e a política social. 3. ed. São Paulo: Cortez, 2009. 